\title{
Cordyline rubra Otto and A. Dietr. Leaf and Fruit Esxtracts Lack Antibacterial Activity and are Non-toxic in vitro
}

\author{
Lindy Mpala', Getmore Chikowe' ${ }^{2}$, lan Edwin Cock ${ }^{1,2, *}$ \\ 'School of Environment and Science, Nathan Campus, Griffith University, Nathan, Brisbane, Queensland, AUSTRALIA. \\ 2Environmental Futures Research Institute, Griffith University, Nathan, Brisbane, Queensland, AUSTRALIA.
}

\begin{abstract}
Introduction: The development of bacterial strains that are resistant to multiple antibiotics has made the development of new antibiotics a priority for medical research. Traditional plant medicines are important leads for the discovery of new medicines. The family Agavaceae is widely used therapeutically in many areas of the world. Despite this, many members of this family are yet to be examined extensively for therapeutic properties. The species Cordyline rubra Otto and A. Dietr. was screened for antibacterial activity in this study. Methods: The ability of $C$. rubra leaf and fruit extracts to inhibit the growth of a panel of bacterial pathogens was investigated by disc diffusion assay. Toxicity was examined using the Artemia franciscana nauplii bioassay. Results: Methanolic $C$. rubra leaf and fruit extracts were completely ineffective at inhibiting the growth of gram-positive and gramnegative panels of bacteria. The extracts were also nontoxic or of low toxicity following $24 \mathrm{~h}$ exposure. Conclusion: C. rubra leaf and fruit extracts were completely ineffective bacterial growth inhibitors. However,
\end{abstract}

these extracts may have other therapeutic properties and testing against protozoa, fungi, virus and tumour cells is required.

Key words: Asparagaceae, Palm lily, Antibiotic resistance, Australian plant, Traditional medicine, Antibacterial activity, Medicinal plants, Toxicity.

\section{Correspondence:}

Dr. Ian Edwin Cock

'Environmental Futures Research Institute, Griffith University, Nathan, Brisbane, Queensland, AUSTRALIA.

${ }^{2}$ Environmental Futures Research Institute, Griffith University, Nathan, Brisbane, Queensland, AUSTRALIA.

Phone no: +61737357637

Email id: I.Cock@griffith.edu.au

DOI: $10.5530 /$ pc.2019.4.27

\section{INTRODUCTION}

The recent increase of bacterial resistance to antibiotics has made the development of new therapies particularly urgent. Bacterial pathogens that are either extremely (XDR) or Totally Drug Resistant (TDR) to common clinically used antibiotics are now common and several bacterial strains have been reported to be resistant to all current antibiotics. ${ }^{1}$ There are now limited therapeutic options for many diseases caused by bacterial pathogens and the situation is expected to worsen in the future as bacteria exchange resistance genes. Indeed, the development of alternative antibacterial treatment modalities has become crucial and is considered by the World Health Organisation (WHO) to be one of the most serious challenges facing medical science. ${ }^{2}$ For a number of reasons reviewed elsewhere, ${ }^{1}$ it is unlikely that the previous methods of antibiotic discovery/development will be as successful in the future and new treatment modalities are urgently required. Traditional medicines and herbal remedies have great potential for antimicrobial drug development and there has recently been a substantial increase in interest in this field. ${ }^{3-7}$

C. rubra (commonly known as palm lily) is an evergreen Australian plant that grows to approximately 4 metres tall (Figure 1a). It grows in warm rainforest and moist eucalytus forests in eastern Australia, from northern New South Wales, to the central Queensland coast. C. rubra has glossy green narrowly elliptical leaves (up to $50 \mathrm{~cm}$ long by $6 \mathrm{~cm}$ wide). Small flowers form on inflorescences (Figure $1 \mathrm{~b}$ ) in spring and develop into small oval shaped red berries (Figure 1c) from which the plant's name is derived. The phytochemistry of the genus Cordyline and of the species C. rubra in particular has been relatively well reported. The genus Cordyline is characterised by relatively high levels of steroidal saponins and cholestane glycosides. A previous study identified the spirostane saponins strictagenin (Figure 1d), rubragenin (Figure 1e), wallogenin (Figure 1f), pompeygenin (Figure 1g) and chenogenin (Figure 1h) in C. rubra leaves. ${ }^{8}$ The same group also identified the furostane saponin $1 \beta$, 3a-dihydroxy-furost-5-ene (Figure 1i) in C. rubra leaves. ${ }^{9}$ More recently, the steroidal saponins fruticodide $\mathrm{H}$ (Figure $1 \mathrm{j}$ ), fruticodide I (Figure 1k) and (l) fruticodide J (Figure 1l) were also identified in C. rubra leaf extracts. ${ }^{10}$ The presence of the high levels and the diversity of steroidal saponins is notable as many similar compounds have cytotoxic, anticancer, antibacterial and antifungal properties. ${ }^{11,12}$ Despite the traditional usage of Cordyline spp. medicinally and the high saponin content of C. rubra, it is yet to be extensively examined for therapeutic properties. This study was undertaken to screen C. rubra leaf and fruit extracts against panels of gram-positive and gram-negative bacterial pathogens.

\section{MATERIALS AND METHODS}

\section{Plant Material}

\section{Collection of Plant Material and Extraction}

Cordyline rubra Otto and A. Dietr. Leaves and fruit were harvested from a confirmed suburban plant in the southern suburbs of Brisbane, Australia. The plant was monitored for 3 months prior to harvesting to ensure that it received no pesticides or fertilisers and none were used in a 3 metre radius of the plant. The harvested leaves and flowers were washed in deionised water and processed within 4 hours of collection. The leaves were dried in a Sunbeam food dehydrator and the dried material was ground to a coarse powder. Individual $1 \mathrm{~g}$ masses of the dried plant material was extracted extensively in 50mL methanol (Ajax, AR grade) for $24 \mathrm{hr}$ at $4^{\circ} \mathrm{C}$ with gentle shaking. The extracts were filtered through filter paper (Whatman No. 54) under vacuum followed by drying by rotary evaporation. The resultant pellet was dissolved in $5 \mathrm{~mL}$ deionised water. The extract was passed through $0.22 \mu \mathrm{m}$ filter (Sarstedt) and stored at $4^{\circ} \mathrm{C}$.

\section{Qualitative Phytochemical Studies}

Phytochemical analysis of the C. rubra leaf and fruit extracts for the presence of saponins, phenolic compounds, flavonoids, phytosteroids, 


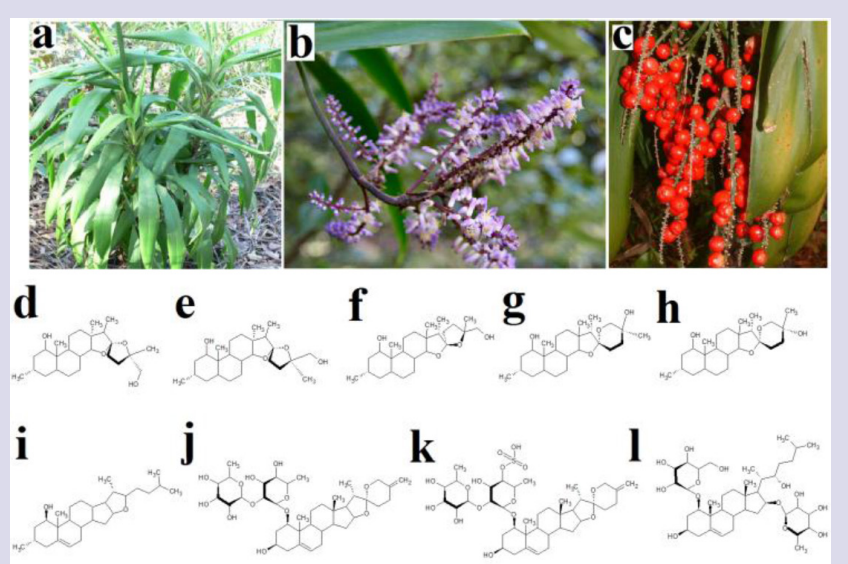

Figure 1: C. rubra (a) whole plant, (b) flowers, (c) fruit, and the structures of previously identified saponins: (d) strictagenin, (e) rubragenin, (f) wallogenin, (g) pompeygenin, (h) chenogenin, (i) 1 $\beta, 3 a-d i h y d r o x y-$ furost-5-ene, (j) fruticodide $\mathrm{H}$, (k) fruticodide $\mathrm{I}$ and (I) $\mathrm{H}$ fruticodide $\mathrm{J}$.

triterpenoids, cardiac glycosides, anthraquinones, tannins and alkaloids was conducted by standard assays. ${ }^{13-15}$

\section{Antibacterial Screening}

\section{Test Microorganisms}

All media was purchased from Oxoid Ltd., Australia. The reference strains of E. coli (ATCC157293), Klebsiella pneumoniae (ATCC31488), Proteus mirabilis (ATCC21721) and Streptococcus pyogenes (ATCC19615) were purchased from American Tissue Culture Collection (ATCC), USA. Clinical isolate microbial strains of Aeromonas hydrophilia, Alcaligenes feacalis, Bacillus cereus, Citrobacter freundii, Pseudomonas fluorescens, Salmonella newport, Serratia marcescens, Shigella sonneii, Staphylococcus aureus and Staphylococcus epidermidis strains were obtained from Ms. Michelle Mendell and Ms. Jane Gifkins, Griffith University. All stock cultures were subcultured and maintained in nutrient broth at $4^{\circ} \mathrm{C}$.

\section{Evaluation of Antimicrobial Activity}

Antimicrobial activity of the C. rubra leaf and fruit extracts extracts was determined using a modified disc diffusion assay. ${ }^{16-18}$ Briefly, $100 \mu \mathrm{L}$ of the each bacterial suspension in log phase was spread onto individual nutrient agar plates and the extracts were tested for antibacterial activity using $6 \mathrm{~mm}$ sterilised filter paper discs. The discs were each infused with $10 \mu \mathrm{L}$ of the individual plant extract, allowed to dry and placed onto the inoculated plates. The plates were allowed to stand at $4^{\circ} \mathrm{C}$ for $2 \mathrm{hr}$ before incubation at $37^{\circ} \mathrm{C}$ for $24 \mathrm{hr}$. The diameters of the zones of inhibition (ZOIs) were measured to the closest whole millimetre. Each assay was performed three times in triplicate $(n=9)$. Mean values $( \pm$ SEM) are reported in this study. Standard discs of ampicillin $(10 \mu \mathrm{g})$ and chloramphenicol $(10 \mu \mathrm{g})$ were obtained from Oxoid, Australia and were used as positive controls to compare antibacterial activity. Filter discs infused with $10 \mu \mathrm{L}$ of distilled water were used as a negative control.

\section{Artemia franciscana Nauplii Toxicity Screening}

Toxicity was tested using an adapted Artemia franciscana nauplii lethality assay. ${ }^{19-21}$ Briefly, A. franciscana nauplii were incubated in the presence of the extracts, reference toxin $(1 \mathrm{mg} / \mathrm{mL}$ potassium dichromate) or artificial seawater (negative control) at $25 \pm 1{ }^{\circ} \mathrm{C}$ under artificial light. All treatments were performed three times in triplicate $(n=9)$. The number of dead were counted in each well at $24 \mathrm{hr}$ and $48 \mathrm{hr}$. At the completion of the $48 \mathrm{hr}$ exposure period, the remaining live nauplii were sacrificed and the total number of nauplii in each well were counted and used to calculate the $\%$ mortality per well. LC $_{50}$ values were calculated for each treatment using probit analysis.

\section{Statistical analysis}

Data are expressed as the mean \pm SEM of three independent experiments with internal triplicates $(n=9)$. One-way ANOVA was used to calculate statistical significance between control and treated groups, with a $P$ value $<0.01$ considered to be statistically significant.

\section{RESULTS}

\section{Liquid extraction yields and qualitative phytochemical screening}

Extraction of $1 \mathrm{~g}$ of dried and powdered C. rubra leaves and fruit with methanol yielded 375 and $268 \mathrm{mg}$ of extracted material respectively (Table 1). The extracts were resuspended in $10 \mathrm{~mL}$ of deionised water (containing 1\% DMSO), resulting in an extract concentration shown in Table 1. Qualitative phytochemical studies showed that both extracts had similar phytochemical profiles. Both contained high levels of phenolic compounds and flavonoids, as well as moderate levels of saponins and lower levels of triterpenoids and tannins. Cardiac glycosides, phytosterols, alkaloids and anthraquinones were completely absent or below the detection thresholds for these assays.

Table 1: The mass of dried extracted material, the concentration after resuspension in deionised water and qualitative phytochemical screenings of the C. rubra leaf and fruit extracts.

\begin{tabular}{|c|c|c|c|c|}
\hline & & & $\begin{array}{c}\text { Leaf } \\
\text { extract }\end{array}$ & $\begin{array}{c}\text { Fruit } \\
\text { extract }\end{array}$ \\
\hline & Mass of ex & Icted material (mg) & 375 & 26.8 \\
\hline & Concentration o & $\begin{array}{l}\text { esuspended extract (mg/ } \\
\mathrm{mL})\end{array}$ & 37.5 & 26.8 \\
\hline & & Total phenols & +++ & +++ \\
\hline & Phenols & Water soluble phenols & +++ & +++ \\
\hline & & Insoluble phenols & ++ & ++ \\
\hline & Saponins & Froth persistence & ++ & ++ \\
\hline & 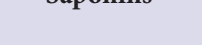 & Emulsion test & ++ & ++ \\
\hline שี & $\begin{array}{l}\text { Cardiac } \\
\text { glycosides }\end{array}$ & Keller-Kiliani Test & - & - \\
\hline ปี & Triterpenoids & Salkowski Test & + & - \\
\hline 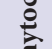 & Phytosterols & Acetic Anhydride Test & - & - \\
\hline $\bar{a}_{0}$ & & Meyer's Test & - & - \\
\hline है & Alkaloids & Wagner's Test & - & - \\
\hline כี & & Draggendoff's Test & - & - \\
\hline$\alpha$ & Flavonoids & Kumar Test & +++ & +++ \\
\hline & Tannins & Ferric Chloride Test & + & + \\
\hline & 106010 & Lead Acetate Test & + & + \\
\hline & Anthraguinones & Free & - & - \\
\hline & & Combined & - & - \\
\hline
\end{tabular}

+++ indicates a large response; ++ indicates a moderate response; + indicates a minor response; - indicates no response in the assay. 


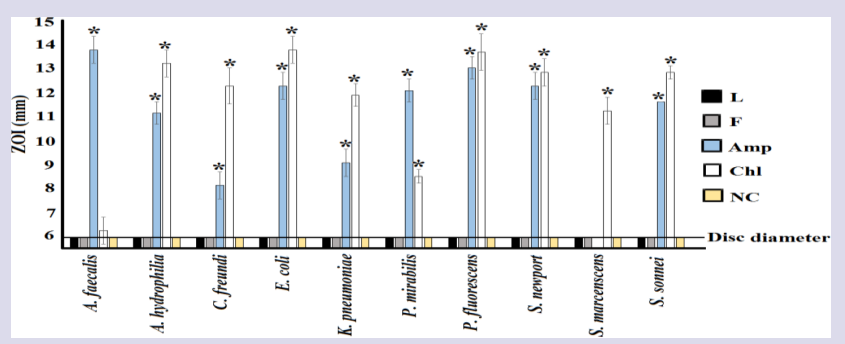

Figure 2: Growth inhibitory activity of $C$. rubra leaf and fruit extracts and reference antibiotics against gram-negative bacterial species measured as ZOls ( $\mathrm{mm}) \pm \mathrm{SEM}$. Ampicillin (Amp) and chloramphenicol (Chl) standard discs $(10 \mu \mathrm{g})$ were used as positive controls. $\mathrm{L}=$ leaf extract; $\mathrm{F}=$ fruit extract; $\mathrm{NC}=$ negative control. All assays were completed three times, each with internal triplicates $(n=9)$ and the results are expressed as mean zones of inhibition $(\mathrm{mm}) \pm \mathrm{SEM}$.

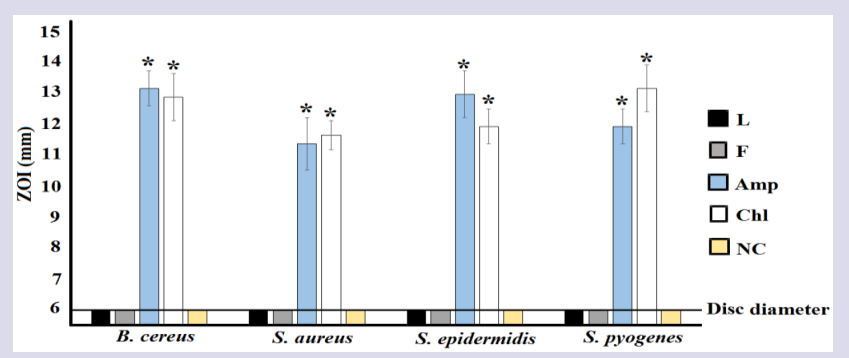

Figure 3: Growth inhibitory activity of $C$. rubra leaf and fruit extracts and reference antibiotics against gram-positive bacterial species measured as ZOls $(\mathrm{mm}) \pm \mathrm{SEM}$. Ampicillin (Amp) and chloramphenicol (Chl) standard discs $(10 \mu \mathrm{g})$ were used as positive controls. $\mathrm{L}=$ leaf extract; $\mathrm{F}=$ fruit extract; $\mathrm{NC}=$ negative control. All assays were completed three times, each with internal triplicates $(n=9)$ and the results are expressed as mean zones of inhibition $(\mathrm{mm}) \pm \mathrm{SEM}$.

\section{Antibacterial activity}

To determine the growth inhibitory activity of the C. rubra leaf and fruit extracts, aliquots $(10 \mu \mathrm{L})$ of each extract were screened in the disc diffusion assay. The C. rubra leaf and fruit extracts were ineffective at inhibiting the growth of all gram-negative (Figure 2) and gram positive (Figure 3) bacterial species tested. In contrast, both positive control antibiotics (ampicillin and chloramphenicol) were effective growth inhibitors, with ZOI's of up to $14.3 \mathrm{~mm}$ (ampicillin against $A$. faecalis). We were therefore unable to determine the MIC values for any extract as they were completely ineffective at all concentrations tested.

\section{Quantification of Toxicity}

The toxicity of the C. rubra leaf and fruit extracts was initially tested at $2 \mathrm{mg} / \mathrm{mL}$ in the A. franciscana nauplii bioassay (Figure 4 ). The mortality in the presence of both extracts was not significantly different to that of the untreated control at $24 \mathrm{hr}$ and thus both extracts were deemed to be non-toxic. Extracts with $24 \mathrm{hr} \mathrm{LC}_{50}$ values $>1000 \mu \mathrm{g} / \mathrm{mL}$ have previously been defined as non-toxic. ${ }^{19}$ In contrast, the potassium dichromate positive control induced substantial mortality within 4 h (results not shown), with $100 \%$ mortality induction seen by $24 \mathrm{hr}$. The mortality increased following exposure to the C. rubra leaf and fruit extracts at $48 \mathrm{hr}$ and was further increased following $72 \mathrm{hr}$ exposure.

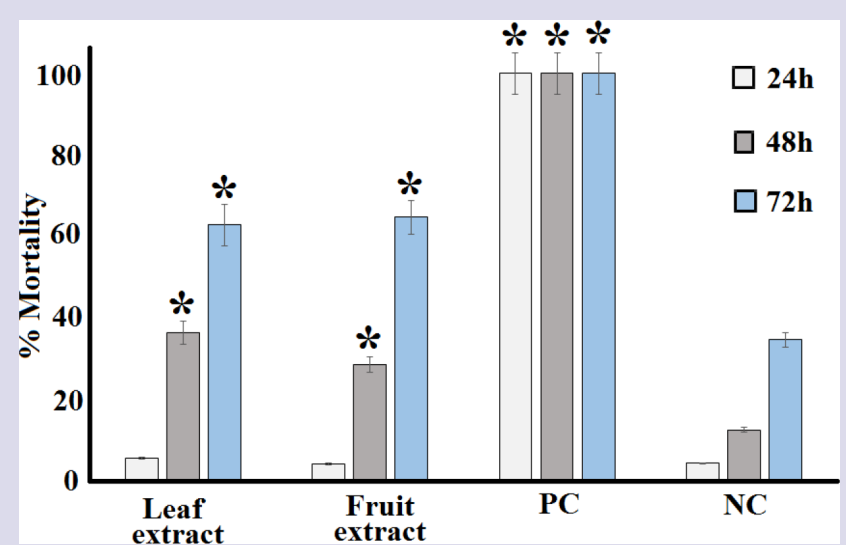

Figure 4: The lethality of the $C$. rubra leaf and fruit extracts, potassium dichromate control $(1000 \mu \mathrm{g} / \mathrm{mL}$ ) and seawater (negative control) following 24,48 and $72 \mathrm{hr}$ of exposaure. All bioassays were performed three times in triplicate $(n=9)$ and are expressed as mean \pm SEM. * indicates results that are significantly different to the untreated (seawater) control at the equivalent exposure time $(P<0.01)$.

\section{DISCUSSION}

With the recent increase in bacterial resistance towards the current repertoire of antibiotics, the development of new medicines to inhibit the growth of bacterial pathogens is a high priority for medical science. ${ }^{1,2}$ A parallel decrease in the discovery of new antibiotic medicines by conventional strategies has increased interest in re-evaluating medicinal plants for new antibiotic chemotherapies. ${ }^{22}$ Whilst we were unable to find records of medicinal usage of C. rubra by the first Australians, it is taxonomically related to other Asparagaceae species with antibacterial activity. $^{23-25}$ and it was therefore deemed a viable target for antibacterial screening. Interestingly, the C. rubra leaf and fruit extracts were completely inactive against all gram-positive and gram-negative bacteria tested.

It is noteworthy that a single assay technique was used to screen for antibacterial activity in this study. We chose to use the disc diffusion assay as it is a rapid methodology and it has previously been widely utilised in other studies. Therefore, comparisons between studies are relatively simple. However, as the disc diffusion method is reliant on the diffusion of a molecule through the aqueous environment of an agar gel, this assay may be affected by the solubility of the extract compounds in the aqueous environment. Polar compounds that are highly soluble in water would be expected to diffuse easily in the gel, whereas less soluble compounds would not diffuse as readily and thus be concentrated around the disc. For this reason, whilst this is a handy assay for screening aqueous extracts, this technique may not be ideal for nonpolar compounds (e.g. when screening essential oil and their components). For examining nonpolar mixtures, other techniques such as liquid dilution assays may be preferred. Thus, liquid dilution studies may be better suited to screen C. rubra leaf and fruit extracts for activity and future studies will use these techniques to re-examine the extracts for antibacterial activity.

Diffusion of molecules within an agar gel is also affected by the size of the molecules. The movement of large, complex phytochemicals (eg. complex tannins) through agar gels by diffusion would also be retarded and may provide a false idea of the efficacy of an extract. As many saponins have well described antibiotic properties, screening for growth inhibition using agar diffusion techniques may give a distorted 
view of its inhibitory potential.

The findings reported here also indicate that the extracts examined were non-toxic $\left(24 \mathrm{hr} \mathrm{LC}_{50}>1000 \mu \mathrm{g} / \mathrm{mL}\right)$ in the Artemia nauplii bioassay. Whilst toxicity was assessed in this study with the test organism A. franciscana, toxicity towards A. franciscana has previously been shown to correlate well with toxicity towards human cells for many toxins. ${ }^{19}$ However, further studies are required to determine whether this is also true for the C. rubra leaf and fruit extracts examined in this study.

\section{CONCLUSION}

Methanolic C. rubra leaf and fruit extracts displayed no antibacterial activity in the disc diffusion assay against a panel of human pathogenic bacteria and were nontoxic towards Artemia nauplii.

\section{ACKNOWLEDGEMENT}

The authors are grateful to Michelle Mendell and Jane Gifkins of Griffith University for providing the clinical bacterial strains used in this study. Financial support for this work was provided by the Environmental Futures Research Institute and the School of Natural Sciences, Griffith University, Australia.

\section{CONFLICT OF INTEREST}

The authors report no conflicts of interest.

\section{ABBREVIATIONS}

DMSO: Dimethyl sulfoxide; $\mathbf{L C}_{50}$ : The concentration required to achieve 50 \% mortality; MIC: Minimum inhibitory concentration; ZOI: Zone of inhibition.

\section{REFERENCES}

1. Cheesman MJ, Ilanko A, Blonk B, et al. Developing new antimicrobial therapies: Are synergistic combinations of plant extracts/compounds with conventional antibiotics the solution?. Pharmacog Rev. 2017;11(22):57-72. DOI: 10.4103/ phrev.phrev_21_17

2. WHO. Antimicrobial Resistance. World Health Organization. 2016. Available from: http://www.who.int/mediacentre/factsheets/fs194/en/. [Cited on 10 May 2017 May 10].

3. Sirdaarta J, Matthews B, Cock IE. Kakadu plum fruit extracts inhibit the growth of the bacterial triggers of rheumatoid arthritis: Identification of stilbene and tannin components. J Funct Foods. 2015;17:610-20. DOI: 10.1016/j.jff.2015.06.019

4. Ilanko A, Cock IE. The interactive antimicrobial activity of contentional antibiotics and Petalostigma spp. extracts against bacterial triggers of some autoimmune inflammatory diseases. Pharmacog J. 2019;11(2):292-309.

5. Hart C, Ilanko P, Sirdaarta J, et al. Tasmannia stipitata as a functional food/ natural preservative: Antimicrobial activity and toxicity. Pharmacog Commn. 2014;4(4):33-47. DOI: 10.5530/pc.2014.4.4

6. Cock IE, WinnettV, Sirdaarta J, et al. The potential of selected Australian medicinal plants with anti-proteus activity for the treatment and prevention of rheumatoid arthritis. Pharmacog Mag. 2015;11(Suppl 1):S190-208. DOI: 10.4103/09731296.157734

7. Winnett V, Sirdaarta J, White A, et al. Inhibition of Klebsiella pneumonia growth by selected Australian plants: Natural approaches for the prevention and management of ankylosing spondylitis. Inflammopharmacol. 2017;25(2):223-35. DOI: $10.1007 / \mathrm{s} 10787-017-0328-1$

8. Yang $\mathrm{MH}$, Blunden $\mathrm{G}$, Patel $\mathrm{A}$, et al. Rubragenin, chenogenin and wallogenin, steroidal sapogenins from Cordyline rubra. Phytochem. 1989;28(11):3171-3.

9. Yang $\mathrm{MH}$, Blunden $\mathrm{G}$, Patel $\mathrm{A}$, et al. Two furostane sapogenins from Cordyline rubra. Phytochem. 1990;29(4):1332-4.

10. Fouedjou RT, Teponno RB, Quassinti L, et al. Steroidal saponins from the leaves of Cordyline fruticosa (L.) A. Chev. and their cytotoxic and antimicrobial activity. Phytochem Lett. 2014;7:62-8.

11. Li M, Wang MY, Li XB. Chemical constituents and biological activities of genus Hosta (Liliaceae). J Med Plants Res. 2012;6(14):2704-13.

12. Sautour M, Mitaine-Offer AC, Lacaille-Dubois MA. The Dioscorea genus: A review of bioactive steroid saponins. J Nat Med. 2007;61(2):91-101.

13. Wright MH, Matthews B, Arnold MSJ, et al. The prevention of fish spoilage by high antioxidant Australian culinary plants: Shewanella putrefaciens growth inhibition. Int J Food Sci Technol. 2016;51(3):801-13. DOI: 10.1111/ijfs.13026

14. Mpala L, Chikowe G, Cock IE. No evidence of antiseptic properties and low toxicity of selected Aloe species. J Pharm Negative Results. 2010;1(1):10-6. DOI: 10.4103/0976-9234.68869

15. Lee CJ, Wright MH, Arnold MSJ, et al. Inhibition of Streptococcus pyogenes growth by native Australian plants: New approaches towards the management of impetigo, pharyngitis and rheumatic heart disease. Pharmacog Commn. 2016;6(3):164-73. DOI: 10.5530/pc.2016.3.6

16. Wright $\mathrm{MH}$, Arnold MSJ, Lee CJ, et al. Qualitative phytochemical analysis and antibacterial activity evaluation of Indian Terminalia spp. Against the pharyngitis causing pathogen Streptococcus pyogenes. Pharmacog Commn. 2016;6(2):85-92. DOI: $10.5530 / p c .2016 .2 .6$

17. Omer E, Elshamy Al, Nassar M, et al. Plantago squarrosa Murray extracts inhibit the growth of some bacterial triggers of autoimmune diseases: GC-MS analysis of an inhibitory extract. Inflammopharmacol. 2018;27(2):375-85. DOI: 10.1007/s10787-018-0547-0

18. Wright MH, Sirdaarta J, White A, et al. GC-MS headspace analysis of Terminalia ferdinandiana fruit and leaf extracts which inhibit Bacillus anthracis growth. Pharmacog J. 2017;9(1):73-82. DOI: 10.5530/pj.2017.1.14

19. Cock IE, Ruebhart DR. Comparison of the brine shrimp nauplii bioassay and the ToxScreen-II test for the detection of toxicity associated with Aloe vera (Aloe barbadensis Miller) leaf extract. Pharmacog Res. 2009;1(2):98-101.

20. Cock IE, Winnett $V$, Sirdaarta J, et al. The potential of selected Australian medicinal plants with anti-proteus activity for the treatment and prevention of rheumatoid arthritis. Pharmacog Mag. 2015;11(Suppl 1):S190-208. DOI: 10.4103/09731296. 157734

21. Hart C, Cock IE. An examination of the antimicrobial and anticancer properties of Garcinia cambogia fruit pericarp extracts. BEMS Reports. 2016;2(1):23-6

22. Aiyegoro OA, Okoh Al. Use of bioactive plant products in combination with standard antibiotics: Implications in antimicrobial chemotherapy. J Med Plants Res. 2009;3(13):1147-52.

23. Moskalenko SA. Preliminary screening of far-eastern ethnomedicinal plants for antibacterial activity. J Ethnopharmacol. 1986;15(3):231-59.

24. Ravishankar K, Kiranmayi GV, Lalitha TM, et al. Preliminary phytochemical screening and in vitro antibacterial activity on Asparagus racemosus root extract. Int J Pharm Chem Biol Sci. 2012;2(1):117-23.

25. Olivier MT, Muganza FM, Shai LJ, et al. Phytochemical screening, antioxidant and antibacterial activities of ethanol extracts of Asparagus suaveolens aerial parts. S Afr J Bot. 2017;108:41-6.

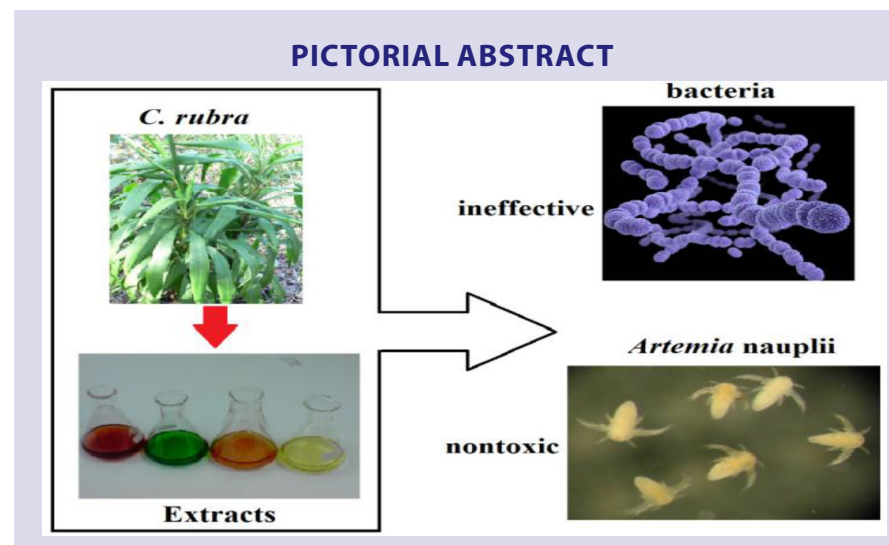

\section{SUMMARY}

- C. rubra leaf and fruit extracts was screened for the ability to block the growth of a panel of human bacterial pathogens.

- No inhibitory activity was evident against any of the bacterial species tested.

- Toxicity of the C. rubra leaf and fruit extracts was determined using the Artemia nauplii toxicity bioassay.

- Both the leaf and fruit extracts were nontoxic 


\section{ABOUT AUTHORS}

Getmore Rumbudzai Chikowe: Ms Getmore Chikowe completed at BSc at Griffith University in life sciences. Following graduation, she undertook a research project in Dr lan Cock's laboratory in the School of Natural Sciences at Griffith University. The project examined the growth inhibitory properties of a variety of Australian native plants against an extensive panel of bacterial pathogens.

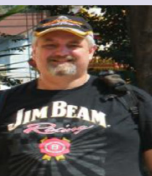

Dr lan Cock: Dr lan Cock leads a research team in the Environmental Futures Research Institute and the School of Environment and Science at Griffith University, Australia. His research involves bioactivity and phytochemical studies into a variety of plant species of both Australian and international origin, including Aloe vera, South Asian and South American tropical fruits, as well as Australia plants including Scaevola spinescens, Pittosporum phylliraeoides, Terminalia ferdinandiana (Kakadu plum), Australian Acacias, Syzygiums, Petalostigmas and Xanthorrhoea johnsonii (grass trees). This range of projects has resulted in nearly 200 publications in a variety of peer reviewed journals.

Lindiwe Nomathemba Mpala: Ms Lindiwe Mpala completed at BSc at Griffith University in life sciences. Following graduation, she undertook a research project in Dr lan Cock's laboratory in the School of Natural Sciences at Griffith University. The project examined the growth inhibitory properties of a variety of Australian native plants against an extensive panel of bacterial pathogens. 